\title{
EVAPORATION RATE OF DISTILLED WATER DROP ON THE SURFACE OF NON-FERROUS METALS
}

\author{
Konstantin Ponomarev ${ }^{1 a}$, Evgeniya Orlova ${ }^{1}$, Dmitry Zaitsev ${ }^{1,2}$ \\ ${ }^{1}$ National Research Tomsk Polytechnic University, 634050 Tomsk, Russia \\ ${ }^{2}$ Kutateladze Institute of Thermophysics, Siberian Branch, Russian Academy of Sciences, 630000 Novosibirsk, \\ Russia
}

\begin{abstract}
We studied experimentally the evaporation process of distilled water drops on the surfaces of non-ferrous metals. Investigations were conducted on the experimental setup using a shadow optical system. The main elements of this system are the source of plane-parallel light and photographic camera. According to the contact diameter change during the evaporation, three stages have been determined (spreading, pinning, depinning). It has been found, that the dependence of evaporation rate on drop volume at low temperatures appear to be well fit by a power function.
\end{abstract}

\section{Introduction}

Usually evaporation of liquid drops on a solid surface is divided into several stages [1-5]. The number of the stages is known to depend on the temperature, surface material and roughness, liquid compound, drop volume, pressure and temperature of the ambient [1-7].

Despite the large number of results obtained by different scientific groups under the supervision of R. D. Deegan [8, 9], D. Brutin [10, 11], R. J. Piknett and R. Bexon [12], H. Erbil and G. McHale [1], V. E. Nakoryakov [3], O. A. Kabov [7, 13] and others, the scientific basis of the process of drop evaporation on a solid surface is not developed sufficiently to predict the change of drop's geometrical characteristics during the evaporation. For this, besides summarizing of the available information [114], it is necessary to study the drop evaporation on poorly studied surfaces of non-ferrous metals (brass, magnalium, copper, aluminum and etc.).

The purpose of this work is to determine the evaporation stages of distilled water drops on the surface of non-ferrous metals and to find out the influence of the liquid volume on the evaporation rate.

\section{Research method}

Experimental investigations were conducted on the setup (Fig. 1) using the shadow optical system $[15,16]$. The main elements of this system are the photographic camera 1 and source of plane-parallel light 3 .

\footnotetext{
a Corresponding author: kotyaponomarev@gmail.com
} 


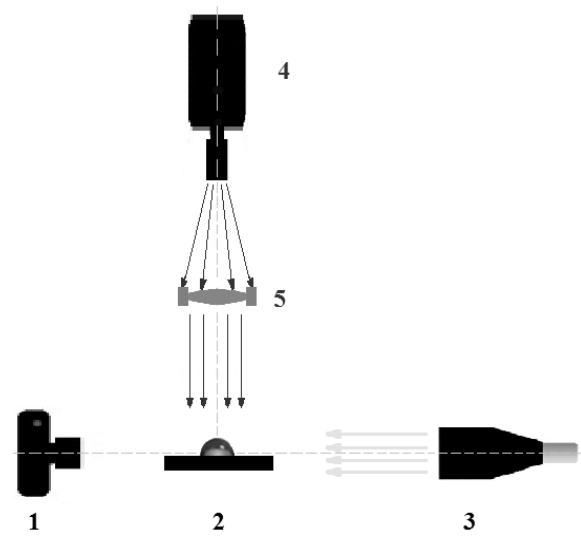

Figure 1. Schematic of the experimental setup: 1 - photographic camera, 2 - substrate with a drop, 3 - source of plane-parallel light, 4 - high-speed video camera, 5 - condensing lens.

The experimental method is described in detail in [16].

We used disk-like substrates made of copper M1 (State All-Union standard 1173-2006) and brass (State All-Union standard 2060-2006) with diameter of $54 \mathrm{~mm}$ and $4 \mathrm{~mm}$ thick.

According to results of a preliminary experiment, the values of influencing parameters were obtained (Table 1).

Table 1. The main influencing parameters

\begin{tabular}{cc}
\hline Parameter & Parameter value \\
\hline Investigated liquid & nondeaerated distilled water \\
\hline Material of the substrate & copper, brass \\
\hline Liquid volume, $\mu 1$ & $10,20,30,40,50,60$ \\
\hline Temperature of the substrate, ${ }^{\circ} \mathrm{C}$ & $40,50,60,70,80$ \\
\hline
\end{tabular}

Output parameters were contact diameter (D) and evaporation rate (W).

\section{Results and discussion}

Time dependences of contact diameter are given in Fig. 2. Initial values of the contact diameter correspond to a moment of drop placement on the substrate, finite values - to a moment of the complete evaporation of the drop.

According to the contact diameter variation, three evaporation stages were determined. The first stage is spreading, which is accompanied by a slight increase of diameter during first 5-10 seconds (not distinctly seen in Fig. 2). Perhaps in the initial moment of time a drop is subjected to molecular adhesion forces from a solid, which pulls out a liquid layer from under a drop, and gravity force, which makes it spread. On the other side, the liquid due to the small volume begins to be heated rapidly. It results in a change of its physicochemical properties; in particular the "solid - liquid" surface tension is reduced. The driving force determined by a decrease in the free surface energy of the system due to changing the contact area between phases is sufficient to overcome micro-asperities on the surface. Resistance force as the wetted surface is increased. Pinning of the three-phase contact line happens during the second stage, when the drop diameter does not change (approximately $85 \%$ of the total evaporation time for temperatures of $40-60{ }^{\circ} \mathrm{C}$ and $80 \%$ for temperatures of $70-80{ }^{\circ} \mathrm{C}$ ). The third stage is depinning, which is accompanied by a decrease of diameter (lasts until the complete evaporation of the drop). Depinning is more pronounced for drops with higher volumes. It is found that the higher the substrate temperature, the longer the third stage in which the diameter decreases. 
(a)



(b)

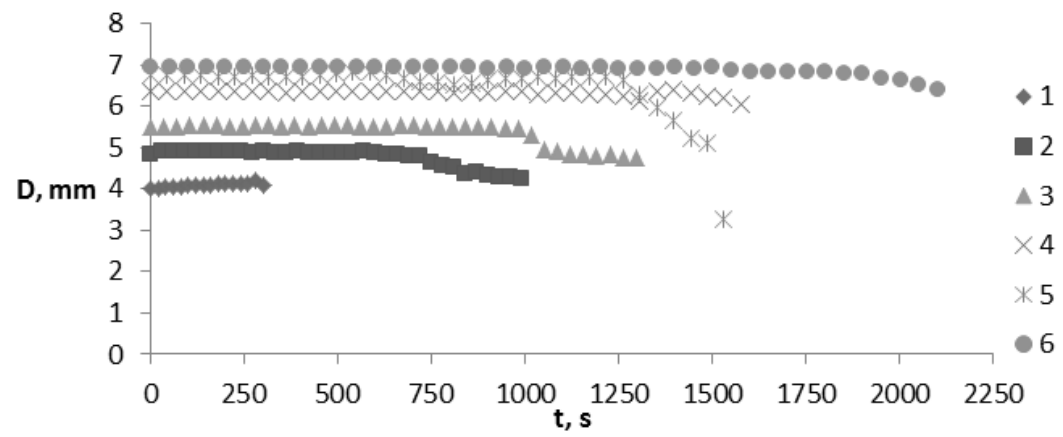

Figure 2. Time dependence of contact diameter during drop evaporation on substrates made of (a) copper; (b) brass, heated to $40^{\circ} \mathrm{C}$. Drop volume was varied: $1-10 \mu \mathrm{l} ; 2-20 \mu \mathrm{l} ; 3-30 \mu \mathrm{l} ; 4-40 \mu \mathrm{l} ; 5-50 \mu \mathrm{l} ; 6-60 \mu \mathrm{l}$.

According to the data available in the literature $[1-5,16]$, it is possible to determine from two [1, $2]$ to four [4, 5] stages of drop evaporation. The reverse order of stages of spreading and pinning was found in [16], where evaporation of drops of $\mathrm{NaCl}$ solution in water on the substrates made of steel, copper and aluminum has been investigated. Pinning with a decrease of contact angle was observed during the first stage; the second stage is spreading, which lasts most of the evaporation time up to crystallization of salts; the third stage - constant contact angle with decreasing diameter during the remaining evaporation time.

The dependences of the drop evaporation rate on drop volume on copper and brass substrates are given in Fig. 3. They appear to be well fit by a power function at low temperatures $40-60{ }^{\circ} \mathrm{C}$ :

$$
w=a \cdot V^{n}
$$



(a)

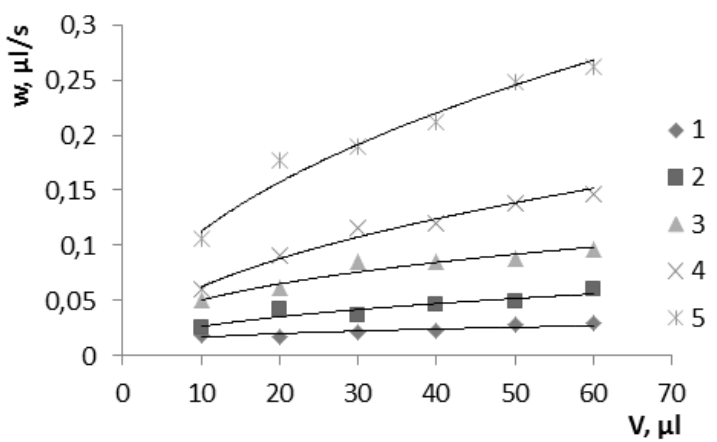

(b)

Figure 3. Evaporation rate of drop versus its volume on the substrate made of: a) copper; b) brass. Substrate temperature: $1-40{ }^{\circ} \mathrm{C} ; 2-50{ }^{\circ} \mathrm{C} ; 3-60{ }^{\circ} \mathrm{C} ; 4-70{ }^{\circ} \mathrm{C} ; 5-80{ }^{\circ} \mathrm{C}$. 


\section{Conclusion}

After conducting experimental investigations of distilled water drop evaporation process on the surface of non-ferrous metals the following results have been obtained:

- Depending on the contact diameter change three stages of evaporation have been determined. The first stage is spreading with a slight increase of the drop diameter. The second is pinning of the contact line caused by increase of resistance force. The last stage is depinning (shrinking of the drop), which lasts until complete evaporation.

- It has been found, that the dependences of the evaporation rate on the drop volume at low temperatures $\left(40-60^{\circ} \mathrm{C}\right)$ appear to be well fit by a power function.

The reported study was supported by RFBR, research project No. 15-38-51066 мол_нр. Тhe shadow optical system was elaborated under the support of Russian Science Foundation (Agreement No. 14-19-01755).

\section{References}

1. H. Erbil, G. Mchale, M. Newton, Langmuir, 18, 2636 (2002)

2. R. Mangel, E. Baer, Chemical Engineering Science, 17, 705 (1962)

3. V. Nakoryakov, S. Misyura, S. Elistratov, Thermal Science, 16, 997 (2012)

4. M. Shanahan, C. Bourges, International Journal of Adhesion and Adhesives, 14, 201 (1994)

5. P. Pittoni, C.-C. Chang, T.-S. Yu, S.-Y Lin, Colloids and Surfaces A: Physicochemical and Engineering Aspects, 432, 89 (2013)

6. A. Panwar, S. Barthwal, S. Ray, Adhesion Science and Technology, 17, 1321 (2003)

7. E. Gatapova, A. Semenov, D. Zaitsev, O. Kabov, Colloids and Surfaces A: Physicochemical and Engineering Aspects, 441, 776 (2014)

8. R. Deegan, O. Bakajin, T. Dupont, G. Huber, S. Nagel, T. Witten, Nature, 389 (1997).

9. R. Deegan, Physical Review E, 61, 1 (2000)

10. B. Sobac and D. Brutin, Langmuir, 27, 24 (2011)

11. A. Diana, M. Castillo, D. Brutin, T. Steinberg, Microgravity Science and Technology, 24, 195 (2012)

12. R. Picknett, R. Bexon, Colloid and Interface Science, 61, 2 (1977)

13. O. Kabov, D. Zaitsev, Doklady Physics 7, 292 (2013)

14. S. Vedantam, M. Panchagnula, Journal of Colloid and Interface Science, 321, 393 (2008)

15. D. Feoktistov, K. Batischeva, E. Orlova, MATEC Web of Conferences, 19, 01001 (2014)

16. E. Orlova, G. Kuznetsov, D. Feoktistov, EPJ Web of Conferences, 76, 012039 (2014) 